\title{
DIVERSIFIKASI EKONOMI RUMAH TANGGA PADA DESA - DESA SEKITAR TAMAN NASIONAL KERINCI SEBLAT DI KABUPATEN LEBONG PROVINSI BENGKULU
}

\section{HOUSEHOLD ECONOMIC DIVERSIFICATION IN VILLAGES AROUND KERINCI SEBALT NATIONAL PARK (TNKS) IN LEBONG DISTRICT, BENGKULU PROVINCE}

\author{
Ketut Sukiyono ${ }^{1)}$, Septri Widiono ${ }^{1)}$, dan Enggar Apriyanto ${ }^{2}$ \\ ${ }^{1) J u r u s a n}$ Sosial Ekonomi Pertanian, ${ }^{2)} J u r u s a n$ Kehutanan \\ Fakultas Pertanian Universitas Bengkulu \\ ksukiyono@yahoo.com
}

\begin{abstract}
Economic diversity has often been promoted as a means to achieve the economic goal of stability. Many empirical studies have also concluded that greater diversification in economic can reduce vulnerability and engendering financial development. The objective of this paper is to analyze the degree of economic diversification at village level. This research was conducted at twenty villages located around Kerinci Seblat National Park (TNKS) and determined purposively and surveyed. Twenty households from each selected village were selected using systematic random sampling method, so the total respondents were 400 households. Economic diversity at the village level was estimated using EDI suggested by Dewi, et al (2005). Research found that EDI value for each village studied varies from 0.20 to 1.00 with no village reaches 1.099, which is an ideal condition. The lowest EDI, i.e. 0.20, occurs in the village of Karang Dapo Atas and Karang Dapo Bawah, subdistrict of Bingin Kuning and the village of Ujung Tanjung II Subdistrict Embong Uram Karang. This value indicates that households in the village surveyed simply rely on one type of work, especially in the agricultural sector. This also means that not many households get into other employment sectors such as mining and or services/stalls/stores. By simply relying on agriculture as its main source of income, households tend to be vulnerable if there is a change in the agricultural sector, especially in sectors such as coffee and rubber plantations.
\end{abstract}

Keywords: Economic Diversity, Kerinci Seblat National Park,

\section{PENDAHULUAN}

Perencanaan pembangunan ekonomi regional yang baik merupakan kunci bagi stabilitas dan pertumbuhan ekonomi suatu wilayah. Pada 
umumnya, pembangunan ekonomi ditujukan untuk dapat memberikan peluang bagi tersedianya lapangan pekerjaan di suatu wilayah, baik tingkat desa, kecamatan atau satuan wilayah yang lebih luas. Kondisi ini juga dipacu oleh perkembangan teknologi dan peningkatan pergerakan barang dan jasa yang telah dapat merubah keseluruhan dasar ekonomi masyarakat. Dari berbagai literatur, seperti penelitian Attaran (1987) dan Moore (2001), dapat ditunjukkan bahwa pembangunan ekonomi di suatu wilayah utamanya ditujukan untuk meningkatkan pertumbuhan ekonomi, menyediakan lapangan pekerjaan, terbukanya peluang usaha, serta menyediakan stabilisasi ekonomi melalui upaya diversifikasi ekonomi pada suatu wilayah. Hal ini dapat dimengerti karena keragaman ekonomi dicirikan oleh tumbuhnya banyak lapangan kerja yang dapat dimasuki dan meningkatkan pertumbuhan ekonomi suatu wilayah.

Lebih jauh, dari berbagai literatur juga sering ditemukan bahwa kajian pembangunan ekonomi sering difokuskan pada analisis pertumbuhan ekonomi. Relatif sedikit ditemukan kajian pembangunan ekonomi yang menekankan pada analisa bagaimana suatu pembangunan dapat memberikan atau menumbuhkan keberagaman lapangan atau sektor pekerjaan yang dapat dimasuki oleh penduduk. Padahal informasi tentang keberagaman sektor pekerjaan yang dapat dan telah dimasuki oleh penduduk sangat penting untuk mengukur sampai sejauh mana suatu wilayah rentan (vulnerability) menghadapi permasalahan perubahan ekonomi (Kort 1981; Malizia and Ke 1993). Misalnya, jatuhnya harga komoditi utama di suatu wilayah atau gagal panen bagi sebagian besar petani akan sangat banyak menekan perekonomian rumah tangga. Namun hal ini akan sangat berkurang dampaknya jika petani memiliki kesempatan untuk memasuki lapangan pekerjaan lain atau di wilayah tersebut tersedia ragam pekerjaan yang dapat dimasuki oleh petani yang rentan terhadap perubahan ekonomi. Oleh sebab itu, kajian tentang keberagaman sektor pekerjaan, yang dikenal dengan Ragam atau Diversifikasi ekonomi menjadi sangat signifikan untuk dilakukan.

Penelitian ini bertujuan untuk mengukur atau mengestimasi ragam ekonomi pada desa-desa sekitar Taman Nasional Kerinci Seblat (TNKS) Kabupaten Lebong. Hal ini penting karena hutan di Provinsi Bengkulu, termasuk hutan lindung dan taman nasional, menghadapi tekanan yang cukup berat seperti ditunjukkan dari laju kerusakan kawasan Taman Nasional Kerinci Sebelat di Propinsi Bengkulu sangat tinggi (Walhi Bengkulu 2008). Walhi Bengkulu melaporkan bahwa awal tahun 2004, dari 340.575 Ha kawasan yang masuk dalam wilayah administrasi propinsi Bengkulu 36,27 \% (123.534,58 ha) telah rusak parah (kondisi non-hutan). Ada dugaan bahwa hutan ini secara berangsur telah dialih-fungsikan oleh masyarakat menjadi berbagai bentuk penggunaan lahan lain seperti pemukiman dan pekarangan, pertanian, kebun dan perkebunan, dan sebagainya. Hal ini semakin tampak pada 
pengamatan visual saat ini. Oleh sebab itu, informasi keragaman ekonomi rumah tangga pada desa-desa penelitian ini akan sangat bermanfaat bagi penyusunan perencanaan pemberdayaan ekonomi masyarakat sekitar hutan, khususnya TNKS, sekaligus mendukung bagi terlaksananya Kabupaten Lebong sebagai kabupaten konservasi.

\section{METODE PENELITIAN}

Lokasi penelitian ini dipilih secara sengaja (purposive) yaitu desa-desa yang berbatasan secara langsung dengan hutan. Identifikasi berdasarkan data yang diperoleh dari kantor kecamatan, terdapat 41 desa yang berbatasan langsung dengan TNKS. Selanjutnya, dari 41 desa ini dipilih sebanyak 20 desa secara acak dan lebih diutamakan pada desa-desa yang berbatasan langsung dengan hutan lindung dan konservasi utamanya dengan Taman Nasional Kelinci Sebelat (TNKS). Selanjutnya dari masing-masing desa dipilih secara acak sistematis (systematic random sampling) sebanyak 20 responden. Responden dalam penelitian ini adalah rumah tangga yang tinggal di desa penelitian terpilih dan tidak ada batasan tentang responden ini. Total responden terpilih adalah sebanyak 400 rumah tangga.

Diversifikasi atau keragaman Ekonomi sering didefiniskan sebagai "distribusi pekerjaan yang seimbang di seluruh industri yang ada" (Attaran, 1987). Sebuah premis secara implisit dan konsisten dengan penelitian sebelumnya menyimpulkan bahwa keragaman ekonomiyang lebih besar akan lebih baik karena keragaman yang tinggi akan mengurangi resiko dan mendorong pertumbuhan finansial (Acemoglu and Zilbotti, 1997; Saint-Paul, 1992). Pada penelitian ini, ragam atau diversifikasi ekonomi pada tingkat desa didefinisikan sebagai keberagaman sumber pendapatan diantara rumah tangga dalam suatu desa. Diversifikasi ekonomi pada tingkat desa diukur dengan Indeks Diversifikasi Ekonomi (Economic Diversity Index atau EDI). EDI, menurut Moore (2001), memberikan indikasi kerentanan masyarakat terhadap perubahan ekonomi. Secara teori, masyarakat dengan perekonomian yang relatif beragam akan dapat beradaptasi dengan baik terhadap perubahan ekonomi yang mempunyai dampak signifikan terhadap suatu sektor pekerjaan. Sebaliknya, jika keberagaman ekonomi kecil, masyarakat akan cenderung mengalami kerentanan terhadap perubahan ekonomi yang terjadi.

Estimasi besaran EDI digunakan rumusan yang digunakan oleh Dewi, et al (2005) dapat diformulasikan sebagai berikut:

$$
E D I=-\sum_{i=1}^{n} p_{i} \ln \left(p_{i}\right)
$$

dimana $p_{i}$ merupakan proporsi rumah tangga pada desa yang hanya tergantung pada sumber pendapatan utama, $i$ adalah $1,2,3, \ldots \mathrm{n}$, dan $\mathrm{n}$ adalah 
jumlah kategori sumber pendapatan utama. Rumah tangga diklasifikasikan ke dalam satu ketegori berdasarkan sumber pendapatan utamanya dan penjumlahan $p_{i}$ sama dengan 1 .

Lebih lanjut, pembagian sumber pendapatan dalam penelitian ini digolongkan menjadi 3 (tiga) jenis sumber pendapatan, yakni pertanian, tambang, dan jasa/warung/toko termasuk di dalamnya pegawai negeri sipil. Pengkategorian sumber pendapatan utama ini juga mengikuti klasifikasi yang digunakan oleh Dewi, et al (2005). Salah satu argumen yang dapat menjelaskan penggunaan klasifikasi ini adalah jenis pekerjaan yang dapat dimasuki oleh rumah tangga relatif terbatas. Umumnya sektor pekerjaan yang dapat dengan mudah dimasuki adalah sektor pertanian yang terdiri dari tanaman pangan, perkebunan, peternakan, perikanan, kehutanan yang umumnya diintegrasikan ke dalam sektor pertanian. Sektor pekerjaan ini merupakan pekerjaan "turun temurun" atau yang "diwarisi" dari orang tua atau pendahulunya. Sementara itu, sektor tambang juga merupakan sektor pekerjaan yang dapat dimasuki, namun sifatnya sangat terbatas. Hal ini berbeda dengan sektor upah, warung, dan toko. Setiap rumah tangga dapat memasuki sektor pekerjaan ini jika memiliki ketrampilan dan modal usaha.

\section{HASIL DAN PEMBAHASAN}

Tabel 1 menyajikan 3 (tiga) sumber pendapatan utama yang dimiliki oleh setiap rumah tangga di desa-desa sekitar TNKS. Sumber pendapatan utama dimaksud disini adalah sumber pendapatan yang memberikan kontribusi terbesar pada pendapatan rumah tangga selama 12 (dua belas) bulan terakhir.

Sesuai dengan kondisi daerahnya yang merupakan areal pedesaan dan masih banyak lahan persawahan dan perkebunan, maka temuan yang menunjukkan bahwa sumber penghasilan utama sebagian besar penduduk di daerah penelitian berasal dari sektor pertanian adalah temuan yang wajar. Secara kumulatif, jumlah rumah tangga yang berkerja di sektor pertanian lebih dari $80 \%$. Sektor pekerjaan lain yang juga banyak dimasuki oleh rumah tangga adalah sektor pertambangan yang menyerap lebih dari 11\% rumah tangga. Sektor tambang yang banyak dimasuki oleh kepala rumah tangga adalah tambang emas tradisional, serta sektor galian pasir dan batu. Lebong adalah salah satu daerah penghasil emas di Provinsi Bengkulu sejak dulu dan saat ini yang berkembang adalah tambang-tambang tradisional. 
Tabel 1. Distribusi Rumah Tangga di Desa-desa Sekitar TNKS di Kabupaten Lebong Berdasarkan 3 (Tiga) Sumber Pendapatan Paling Penting, 2012 (\% Rumah Tangga)

\begin{tabular}{rlrrr}
\hline & & \multicolumn{3}{c}{ Sumber Pendapatan } \\
No & \multicolumn{1}{c}{ Jenis Pekerjaan } & \multicolumn{1}{c}{$\mathbf{1}$} & \multicolumn{1}{c}{$\mathbf{2}$} & \multicolumn{1}{c}{$\mathbf{3}$} \\
\cline { 3 - 5 } & & 4.00 & 1.00 & 0.00 \\
\hline 1 & Dagang & 0.25 & 0.00 & 0.00 \\
2 & Fee kayu & 4.50 & 0.80 & 0.00 \\
3 & Gaji PNS atau swasta & 2.75 & 0.00 & 0.00 \\
4 & Dukungan keluarga & 16.50 & 2.80 & 0.00 \\
5 & Karet & 1.00 & 0.00 & 0.00 \\
6 & Rotan & 0.00 & 0.00 & 0.00 \\
7 & Sarang burung & 0.50 & 0.80 & 0.00 \\
8 & Kayu & 0.00 & 0.00 & 0.00 \\
9 & Kerajinan tangan & 0.75 & 2.20 & 0.00 \\
10 & Kios/Warung/Toko & 1.00 & 0.00 & 0.00 \\
11 & Fee lain/ganti rugi & 0.25 & 0.20 & 0.20 \\
12 & Honor pengurus kampong & & \\
13 & Pertanian (padi, sayur, kopi, ternak , & 56.00 & 6.80 & 1.20 \\
& tambak) & 0.25 & 0.50 & 1.80 \\
14 & Ikan (dari sungai atau danau) & 0.00 & 0.20 & 0.00 \\
15 & Gaharu & 0.00 & 0.80 & 0.20 \\
16 & Berburu & 0.25 & 1.00 & 0.00 \\
17 & Hasil hutan lainnya & 0.50 & 2.20 & 0.00 \\
18 & Pelayanan (tukang, bengkel, dll) & 11.50 & 16.20 & 2.80 \\
19 & Tambang & 0.00 & 64.50 & 93.80 \\
20 & Tidak memiliki sumber pendapatan & & \\
& lainnya & 100.00 & 100.00 & 100.00 \\
\hline & Total & & \\
\hline
\end{tabular}

Sumber: data primer diolah (2012), $n=400$ rumah tangga

Hasil penelitian juga menunjukkan bahwa lebih dari $64 \%$ rumah tangga tidak memiliki pekerjaan sampingan. Dengan kata lain, 36\% memiliki pekerjaan sampingan dimana yang dimasuki utamanya adalah sektor pekerjaan tambang dan pertanian secara umum. Data ini menginformasikan bahwa sektor pertanian merupakan sektor yang sangat penting dalam menyerap tenaga kerja dan menyediakan lapangan kerja. Oleh karena itu, peranan sektor pertanian yang begitu besar dalam penciptaan kesempatan kerja terutama di daerah pedesaan perlu ditinjau dan dikaji secara sungguhsungguh dan mendasar. Suatu usaha yang mampu menciptakan penambahan 
nilai output perlu dilakukan, misalnya dengan cara meningkatkan investasi dan memanfaatkan sumber daya alam secara optimal dengan mengembangkan teknologi industri berorientasi pada pertanian.

Dengan keragaan sektor pekerjaan seperti yang dijelaskan di atas, maka indeks diversifikasi ekonomi pada tingkat desa dapat diestimasi, seperti yang disajikan pada Tabel 2. Indeks Diverifikasi Ekonomi setiap desa yang menjadi lokasi penelitian didefinisikan sebagai ragam sumber pendapatan di antara rumah tangga dalam desa. Secara teknis, indeks diversifikasi ekonomi yang digunakan pada penelitiian dikenal sebagai indeks Shannon dan Weaver atau indeks entropi (Dewi et al 2005). Hal ini di dasarkan pada perkiraan proporsi tenaga kerja pada sektor pekerjaan di masing-masing desa dan menghitung logaritma natural dari proporsi mereka. Proporsi nilai sektor atau jenis pekerjaan dikalikan dengan logaritma naturalnya dan nilai indeks akhir adalah penjumlahan dari semua jenis pekerjaan yang ada. Dalam ekonomi sangat beragam, kerja akan didistribusikan secara adil di semua sektor pekerjaan dan 3 (tiga) jenis pekerjaan yang membawa nilai indeks maksimum 1.099 sedangkan dalam ekonomi sangat terkonsentrasi, semua pekerjaan akan berada dalam satu sektor industri dan yang membawa nilai indeks untuk nol.

Nilai indeks untuk masing-masing desa penelitian di Kabupaten Lebong bervariasi 0,20 - 1,00 dengan tidak ada daerah yang mencapai nilai 1,099 sebagai kondisi yang ideal. Indeks diversifikasi ekonomi (EDI) terendah dengan nilai EDI sebesar 0,20 terjadi di desa Karang Dapo Atas dan Karang Dapo Bawah di Kecamatan Bingin Kuning dan desa Ujung Tanjung II Kecamatan Embong Uram. Nilai ini mengindikasikan bahwa rumah tangga di desa-desa ini relatif hanya mengandalkan satu jenis pekerjaan, khususnya sektor pertanian. Hasil ini juga mengindikasikan bahwa tidak banyak rumah tangga yang memasuki sektor pekerjaan lain seperti sektor tambang dan atau jasa/warung/toko.

Dengan hanya mengandalkan sektor pertanian sebagai sumber pendapatan utamanya, rumah tangga cenderung rentan jika terjadi perubahan pada sektor pertanian, khususnya sektor perkebunan seperti kopi dan karet yang banyak diusahakan oleh petani. Jatuh dan fluktuasi harga kopi merupakan permasalahan yang sering terjadi dan dihadapi petani dan dapat menyebabkan rumah tangga petani kopi jatuh miskin. Namun demikian, yang perlu diingat bahwa usaha di bidang pertanian bukan berarti hanya satu jenis usaha, petani di daerah pertanian juga mengusahakan ternak sapi, ayam, dan ikan, usahatani tanaman pangan, serta pemanfaatan pekarangan yang juga menjadi sumber pendapatan dan sumber pangan bagi rumah tangga. Hal ini akan tampak lebih jelas jika diikuti dengan kajian indeks diversifikasi pendapatan rumah tangga. 
Tabel 2. Indeks Ragam Sumber Pendapatan Pada Desa - desa Sekitar TNKS di Kabupaten Lebong, 2012

\begin{tabular}{rlll}
\hline No & \multicolumn{1}{c}{ Kecamatan } & \multicolumn{1}{c}{ Desa } & EDI \\
\hline 1 & Bingin Kuning & Karang Dapo Atas & 0.20 \\
2 & & Karang Dapo Bawah & 0.20 \\
3 & & Pelabuhan Talang Leak & 0.39 \\
4 & & Talang Leak I & 0.50 \\
5 & Embong Uram & Air Kopras & 0.73 \\
6 & & Kota Baru & 0.42 \\
7 & & Talang Sakti & 0.33 \\
8 & & Tambang Sawah & 1.00 \\
9 & & Ujung Tanjung II & 0.20 \\
10 & Lebong Atas & Atas Tebing & 0.64 \\
11 & & Kota Baru & 0.69 \\
12 & & Danau & 0.42 \\
13 & & Pelabi & 0.73 \\
14 & Pinang Pelapis & Ketenong I & 0.42 \\
15 & & Ketenong II & 1.00 \\
16 & & Seblat Ulu & 0.33 \\
17 & Rimbo Pengadang & Air Dingin & 0.80 \\
18 & & Talang Ratu & 0.94 \\
19 & Topos & Talang Baru & 0.52 \\
20 & & Talang Donok & 0.56 \\
\hline
\end{tabular}

Sumber: data primer diolah (2012)

Ada tiga desa yang memiliki nilai EDI hampir ideal seperti desa Tambang Sawah, Ketenong II, Talang Ratu dan Air Dingin yang masingmasing memiliki nilai EDI di atas 1 dan 0,94. Indikator ini menunjukkan bahwa rumah tangga hampir didistribusikan secara merata pada sektor sektor pekerjaan yang ada di desa. Dengan kata lain, rumah tangga yang ada di desa - desa ini tidak terkonsentrasi pada satu jenis pekerjaan. Dekatnya dengan lokasi tambang menyebabkan banyak rumah tangga yang dapat memasuki sektor perkerjaan tambang, dimana pada gilirannya banyak juga sektor lain yang dapat berkembang dan dimasuki oleh rumah tangga, khususnya warung dan toko atau jasa lain seperti bengkel.

Jika diklasifikasikan desa-desa penelitian berdasarkan keragaman ekonominya maka desa dapat digolongkan menjadi 3 kategori yaitu beragam, sedang dan tidak beragam. Hasil klasifikasi desa-desa berdasarkan keragaman ekonomi daerahnya disajikan pada Tabel 3.

Tabel 3 menunjukkan bahwa hanya 20 persen desa yang menjadi lokasi penelitian mempunyai keanekaragaman perekonomian yang tinggi dengan sumber pendapatan di desa-desa ini yang cukup heterogen. Hal ini 
mengindikasikan bahwa jumlah rumah tangga di desa-desa ini yang masuk pada tiga jenis pekerjaan relatif sama seperti telah dikemukakan, indikator ini (EDI) digunakan untuk mengetahui "keanekaragaman" dari sumber pendapatan rumah tangga di desa-desa sekitar TNKS. Sumber pendapatan paling beragam terjadi ketika semua sumber pendapatan yang ada di desa dan memiliki proporsi jumlah rumah tangga yang memasukinya relatif sama.

Tabel 3. Klasifikasi Desa-desa Sekitar TNKS di Kabupaten Lebong Berdasarkan Keragaman Ekonominya, 2012

\begin{tabular}{|c|c|c|c|c|c|}
\hline \multicolumn{2}{|c|}{ Beragam $(0,73-1,00)$} & \multicolumn{2}{|c|}{ Sedang $(0,48-73)$} & \multicolumn{2}{|c|}{ Tidak Beragam $(0,20-0,47)$} \\
\hline Kecamatan & Desa & Kecamatan & Desa & Kecamatan & Desa \\
\hline Embong & Tambang & Bingin & Talang & Bingin & Pelabuhan Talang \\
\hline Uram & Sawah & Kuning & Leak I & Kuning & Leak \\
\hline $\begin{array}{l}\text { Pinang } \\
\text { Pelapis }\end{array}$ & Ketenong II & $\begin{array}{l}\text { Embong } \\
\text { Uram }\end{array}$ & Air Kopras & & Karang Dapo Atas \\
\hline $\begin{array}{l}\text { Rimbo } \\
\text { Pengadang }\end{array}$ & Talang Ratu & $\begin{array}{l}\text { Lebong } \\
\text { Atas }\end{array}$ & Pelabi & & $\begin{array}{l}\text { Karang Dapo } \\
\text { Bawah }\end{array}$ \\
\hline & Air Dingin & & Kota Baru & $\begin{array}{l}\text { Embong } \\
\text { Uram }\end{array}$ & Kota Baru \\
\hline & & & $\begin{array}{l}\text { Atas } \\
\text { Tebing }\end{array}$ & & Talang Sakti \\
\hline & & Topos & $\begin{array}{l}\text { Talang } \\
\text { Donok }\end{array}$ & & Ujung Tanjung II \\
\hline & & & $\begin{array}{l}\text { Talang } \\
\text { Baru }\end{array}$ & $\begin{array}{l}\text { Lebong } \\
\text { Atas }\end{array}$ & Danau \\
\hline & & & & $\begin{array}{l}\text { Pinang } \\
\text { Pelapis }\end{array}$ & Ketenong I \\
\hline & & & & & Seblat Ulu \\
\hline
\end{tabular}

Sumber: data primer diolah (2012)

Hasil analisis juga menunjukkan bahwa 45 persen desa-desa sekitar TNKS tidak memiliki keragaman ekonomi. Artinya, sebagian besar rumah tangga di desa-desa ini hanya bertumpu pada satu jenis pekerjaan sebagai sumber pendapatan utamanya dan tidak banyak jenis pekerjaan yang tersedia di desa yang memungkinkan dimasuki oleh rumah tangga untuk dijadikan sebagai sumber pendapatan utamanya. Faktor lain yang diduga menyebabkan terjadinya kondisi ini adalah rendahnya tingkat pendidikan yang dimiliki oleh rumah tangga sehingga mereka menjadi kurang kreatif atau inovatif untuk dapat mengembangkan atau memasuki usaha yang dapat dijadikan sumber pendapatan utama rumah tangga. Alasan lain adalah sektor pekerjaan yang dimasuki saat ini merupakan jenis pekerjaan yang sangat dikuasai oleh rumah tangga sehingga rumah tangga menjadi sulit untuk bertransformasi ke luar sektor yang saat ini digeluti. Jika dilihat dari jenis lapangan pekerjaan yang dimasuki dan kondisi lingkungan desa, maka sektor pertanian secara umum tampaknya menjadi sumber pendapatan utamanya. 


\section{SIMPULAN DAN IMPLIKASI}

Hasil penelitian menunjukkan nilai indeks diversifikasi ekonomi untuk masing - masing desa penelitian di Kabupaten Lebong bervariasi 0,20 - 1,00. Tidak ada satu daerah atau desa yang mencapai nilai 1,099 yang merupakan kondisi ideal. Hasil penelitian ini mengindikasikan bahwa rumah tangga di desa-desa ini relatif hanya mengandalkan satu jenis pekerjaan, khususnya sektor pertanian. Ini juga berarti tidak banyak rumah tangga yang memasuki sektor pekerjaan lain seperti sektor tambang dan atau jasa/warung/toko.

Ada dua hal yang perlu dicatat dari penggunaan EDI sebagai indikator keragaman ekonomi suatu desa. Jika keragaman ekonomi didefinisikan sebagai kehadiran berbagai jenis pekerjaan di desa atau sejauh mana kegiatan ekonomi atau pekerjaan suatu desa didistribusikan di antara sejumlah kategori pekerjaan sehingga dapat digunakan sebagai sumber pendapatan utama, maka informasi ini sangat berguna untuk menggambarkan keragaman desa dan membandingkannya dengan desa yang lain. Namun demikian, penggunaan indikator ini juga dapat menyesatkan, karena jika suatu desa didominasi oleh satu jenis sumber pendapatan, tidak beragam dan memang desa ini hanya cocok atau sesuai dengan satu jenis sumber pendapatan, atau desa ini lebih baik menutup dari jenis pekerjaan lain. Adanya jenis pekerjaan tambang yang juga dijadikan sebagian rumah tangga sebagai pendapatan utama, misalnya, banyak dilakukan pada kawasan hutan lindung sehingga hal ini akan dapat menyebabkan degradasi lahan atau kualitas lingkungan. Oleh sebab itu, penggunaan indikator EDI ini harus diterjemahkan secara hati-hati dan secara umum, ekonomiyang beragam adalah ekonomi yang sehat.

\section{SANWACANA}

Penelitian ini merupakan bagian dari penelitian Unggulan Perguruan Tinggi dengan Judul "Perancangan Strategi Pemberdayaan Ekonomi Masyarakat Sekitar Hutan Sebagai Upaya Mengurangi Tekanan Penduduk Pada Kawasan Sekitar Hutan Lindung " yang dibiayai oleh Dana DIPA UNIB 0824/023-04.2.16/08/2012 Tanggal 9 Desember 2011 Berdasarkan Surat Perjanjian Nomor 2102/UN30.10.06.01/HK/2012 Tanggal 2 Maret 2012. Peneliti mengucapkan terima kasih atas kepercayaan dan dibiayainya untuk melaksanakan penelitian ini.

\section{DAFTAR PUSTAKA}

Acemoglu, Daron, and Zilibotti, Fabrizo. 1997. Was Prometheus Unbound by Chance? Risk, Diversification, and Growth. Journal of Political Economy, 105(4): 709 - 51. 
Attaran, M., 1987. Industrial Diversity and Economic Performance in US Areas. Annuals of Regional Science. XX: 44-54.

Dewi, Sonya, Brian Belcher And Atie Puntodewo. 2005. Village Economic Opportunity, Forest Dependence, And Rural Livelihoods In East Kalimantan, Indonesia. World Development. 33 (9): 1419-1434.

Kort, J.R. 1981. "Regional Economic Instability and Industrial Diversification in the US". Land Economics. 57(4): 596-608.

Malizia EE, and Ke S. 1993. The influence of economic diversity on employment and stability. J Reg. Sci. 33(2): 221-235.

Moore, E. 2001. Measuring Economic Diversification. Oregon Employment Department, USA, diunduh dari:

www.co.lane.or.us/Departments/CAO/EconomicDevelopment/Doc uments/Measuring_Economic_Diversification.pdf pada tanggal 5 Oktober 2012 jam 10.00.

Saint-Paul, Gilles. 1992. Technological Choice, Financial Markets and Economic Development. European Economic Review. 4(36): 763-781.

WALHI BENGKULU. 2008. Kerusakan Hutan Taman Nasional Kerinci Sebelat Wilayah Kabupaten Lebong, Propinsi Bengkulu. Diunduh dari http://cfors.wordpress.com/2008/03/14/kerusakan-hutan-tamannasional-kerinci-sebelat-wilayah-kabupaten-lebong-propinsibengkulu. pada tanggal 17 Juli 2011, jam 11.00. 